\title{
The osteoporosis care gap in Canada
}

\section{A Papaioannou*1, L Giangregorio ${ }^{2}$, B Kvern³ ${ }^{3}$ P Boulos ${ }^{1}$, G Ioannidis ${ }^{4}$ and JD Adachi ${ }^{1}$}

\author{
Address: ${ }^{1}$ Department of Medicine, McMaster University, Hamilton, Canada, ${ }^{2}$ Department of Kinesiology, McMaster University, Hamilton, \\ Canada, ${ }^{3}$ Department of Family Medicine, University of Manitoba, Winnipeg, Canada and ${ }^{4}$ Charlton Medical Centre, Hamilton, Canada \\ Email: A Papaioannou* - papaioannou@hhsc.ca; L Giangregorio - giangrlm@mcmaster.ca; B Kvern - bkvern@cc.UManitoba.ca; \\ P Boulos - boulosp@mcmaster.ca; G Ioannidis - g.ioannidis@sympatico.ca; JD Adachi - jd.adachi@sympatico.ca \\ * Corresponding author
}

Published: 06 April 2004

BMC Musculoskeletal Disorders 2004, 5: I I
Received: 04 September 2003

Accepted: 06 April 2004

This article is available from: http://www.biomedcentral.com/I47/-2474/5/II

(C) 2004 Papaioannou et al; licensee BioMed Central Ltd. This is an Open Access article: verbatim copying and redistribution of this article are permitted in all media for any purpose, provided this notice is preserved along with the article's original URL.

\begin{abstract}
Background: The presence of a fragility fracture is a major risk factor for osteoporosis, and should be an indicator for osteoporosis diagnosis and therapy. However, the extent to which patients who fracture are assessed and treated for osteoporosis is not clear.

Methods: We performed a review of the literature to identify the practice patterns in the diagnosis and treatment of osteoporosis in adults over the age of 40 who experience a fragility fracture in Canada. Searches were performed in MEDLINE (1966 to January 2, 2003) and CINAHL (1982 to February I, 2003) databases.

Results: There is evidence of a care gap between the occurrence of a fragility fracture and the diagnosis and treatment of osteoporosis in Canada. The proportion of individuals with a fragility fracture who received an osteoporosis diagnostic test or physician diagnosis ranged from $1.7 \%$ to $50 \%$. Therapies such as hormone replacement therapy, bisphosphonates or calcitonin were being prescribed to $5.2 \%$ to $37.5 \%$ of patients. Calcium and vitamin D supplement intake was variable, and ranged between $2.8 \%$ to $61.6 \%$ of patients.
\end{abstract}

Conclusion: Many Canadians who experience fragility fracture are not receiving osteoporosis management for the prevention of future fractures.

\section{Background}

Osteoporosis has been described as a silent disease until an individual experiences a fragility fracture, typically occurring at the wrist, vertebra or the hip. The National Institutes of Health consensus conference has modified the original definition of osteoporosis to include "a skeletal disorder characterized by compromised bone strength, predisposing a person to an increased risk of fracture.
Bone strength reflects the integration of two main features bone density and bone quality" [1].

A fragility fracture is a major risk factor for osteoporosis, and has been identified as the only clinically relevant marker of bone quality. These fractures typically occur when an individual falls from a standing height or less. However vertebral and rib fractures often occur without a traumatic event such as during coughing [2]. A history of 
fragility fracture after the age of 40 years increases the risk of a subsequent fracture by 2 - to 9 -fold $[3,4]$. Therapeutic options, such as raloxifene, alendronate, risedronate, can reduce the number of new vertebral compression fractures by $40-60 \%$ within the first year in individuals with a fracture [5]. It is important to identify whether patients who experience fragility fracture are being assessed and treated for osteoporosis in order to reduce the risk of future fracture.

Inadequate osteoporosis evaluation and treatment following fragility fracture has been documented in countries other than Canada [6-13]. A large retrospective cohort study in the United States found that only $2.8 \%$ of women who had experienced a distal radius fracture underwent densitometry and $22.9 \%$ of the women were prescribed osteoporosis treatment [7]. Between 1997 and 2000 in an American retrospective cohort study, only 13\% of those who had experienced hip fractures received supplemental calcium, and $6 \%$ actually received an antiresorptive medication [8].

If an osteoporosis care gap exists, it is essential that primary care physicians and specialists be made aware of it in order to improve the standard of care. The purpose of this review is to identify the practice patterns in the diagnosis and treatment of osteoporosis in adults over the age of 40 who experience a fragility fracture in Canada.

\section{Methods}

In order to identify articles that evaluated osteoporosis diagnosis and treatment after fragility fracture in Canada, a literature search was performed in MEDLINE (1966 to January 2, 2003) and CINAHL (1982 to February 1, 2003) databases, using the key words osteoporosis [Diagnosis, Prevention and Control, Diet Therapy, Drug Therapy, Surgery, Therapy]; hip fractures; femoral fractures; radius fractures; spinal fractures; and Canada. Additional articles were identified by consultation with experts and hand searching of the references of retrieved articles.

Selection criteria for retrieved articles included an evaluation of the diagnosis and/or initiation of treatment for osteoporosis in individuals over the age of 40 years after experiencing a fragility fracture. A physician's clinical diagnosis and/or dual-energy $\mathrm{x}$-ray absorptiometry (DXA) were recorded as osteoporosis diagnosis outcomes. Treatment outcomes included calcium, vitamin $\mathrm{D}$, hormone replacement therapy (HRT), bisphosphonates (etidronate, alendronate, risedronate), calcitonin, and selective estrogen receptor modulators (raloxifene). Studies were excluded if fractures were a result of malignancy or trauma. The proportion of patients receiving an osteoporosis diagnosis and/or each form of treatment was recorded.
Using the above search strategy, ten articles were identified, one of which met the a priori selection criteria. Two articles were identified via consultation with experts, and another was included after hand searching the reference lists. In order to provide a description of the quality of the studies, a list of questions were derived based on some of the quality criteria for assessment of observational studies outlined previously [14].

\section{Results}

The characteristics of the included studies are listed in Table 1. Four studies met the inclusion criteria, and the patient characteristics are listed in Table 2. These studies included patients, aged 50-97 years, discharged from acute care [15-17] and fracture clinics [18] in major urban centres with access to bone densitometry and osteoporosis specialists. In all studies, patients were selected by the reviewing of medical records to identify individuals who fractured. The sample sizes for each study were not determined a priori, but based on the number of individuals identified in the medical records that agreed to participate. In the fracture clinic study, the most common type of fracture was wrist fracture $(77.3 \%)$, and of these, $72.4 \%$ were deemed to be fragility fractures. Vertebral fractures comprised $0.5 \%$ of the number of fractures seen at a fracture clinic [18]. Two studies of hip fractures in acute care settings revealed that only $1.7 \%$ to $14.5 \%$ of those with fracture received a diagnosis of osteoporosis [17]. Up to $40 \%$ of patients had experienced a prior fragility fracture when they were initially identified (index fracture). Subsequent fractures within $1-3$ years occurred in up to $14 \%$ of patients. The criteria used to make a diagnosis of osteoporosis varied across studies, from the use of densitometry to the presence of a fragility fracture (Table 3 ). The proportion of individuals who had a clinical diagnosis of osteoporosis or a bone mineral density test ranged from $1.7 \%$ to $50 \%$, depending on the type of fracture.

Calcium supplements were cited as osteoporosis treatment in $7.6 \%$ to $32 \%$ of patients after fracture. Only $2.8 \%$ to $13 \%$ of patients were taking vitamin $\mathrm{D}[15,18]$. In some cases authors did not differentiate between calcium, vitamin D, or multivitamin use $[16,17]$. HRT or bisphosphonates were prescribed less frequently. One study indicated that $1.4 \%$ of women were taking HRT [19]. Individuals on bisphosphonates ranged from $5.2 \%$ to $16 \%[15,18]$. A study of wrist fractures that did not differentiate between osteoporosis-specific therapies reported that $37.5 \%$ were taking some form of treatment [16].

\section{Discussion}

These studies provide evidence that many Canadians who experience fragility fracture are not being diagnosed or treated for the prevention of future fractures. The prevalence of bone mass measurements or physician follow-up 
Table I: Study Design Characteristics

\begin{tabular}{|c|c|c|c|c|}
\hline & Hajcsar $(2000)^{18}$ & Papaioannou (2000) ${ }^{17}$ & Khan $(2001)^{16}$ & Juby $(2002)^{15}$ \\
\hline Setting & $\begin{array}{l}\text { Three Ontario Community } \\
\text { Hospital Fracture Clinics }\end{array}$ & $\begin{array}{l}\text { Four Tertiary Care Hospitals, } \\
\text { Hamilton }\end{array}$ & $\begin{array}{l}\text { One Tertiary Care Hospital, } \\
\text { Edmonton }\end{array}$ & $\begin{array}{l}\text { One Tertiary Care Hospital, } \\
\text { Edmonton }\end{array}$ \\
\hline Sample & $\begin{array}{l}56.1 \% \text { of patients with fragility } \\
\text { fracture }\end{array}$ & All patients with hip fracture & $\begin{array}{l}72 \% \text { of patients with fragility } \\
\text { fracture of distal radius/ulna }\end{array}$ & $\begin{array}{l}\text { All patients with new hip } \\
\text { fracture }\end{array}$ \\
\hline Participant Selection & Medical records & Medical records & Medical records & Medical records \\
\hline Inclusion Criteria & $\begin{array}{l}\text { Age }>18 \text { years No secondary } \\
\text { causes of bone loss, no significant } \\
\text { trauma }\end{array}$ & $\begin{array}{l}\text { Age } \geq 50 \text { years, Hip fracture, not } \\
\text { hospitalized for motor vehicle } \\
\text { accident or malignancy }\end{array}$ & $\begin{array}{l}\text { Age }>40 \text { years, No significant } \\
\text { trauma }\end{array}$ & $\begin{array}{l}\text { Age }>65 \text { years, New hip } \\
\text { fracture }\end{array}$ \\
\hline $\begin{array}{l}\text { When were participants } \\
\text { assessed? }\end{array}$ & I year post-fracture & $\begin{array}{l}\text { Acute care records and I year post- } \\
\text { fracture }\end{array}$ & $\begin{array}{l}6 \text { months to } 3 \text { years post- } \\
\text { fracture }\end{array}$ & $\begin{array}{l}\text { Acute care and after } \\
\text { rehabilitation }\end{array}$ \\
\hline $\begin{array}{l}\text { How were outcomes } \\
\text { determined? }\end{array}$ & Telephone interview & $\begin{array}{l}\text { Medical records and telephone } \\
\text { interview }\end{array}$ & Telephone interview & Medical records \\
\hline
\end{tabular}

Table 2: Patient Characteristics

\begin{tabular}{|c|c|c|c|}
\hline Study & Patients & Fracture Type & Prior Fracture, Subsequent Fracture \\
\hline Hajcsar $(2000)^{18}$ & $\begin{array}{l}N=108(89 \% \mathrm{~F}, \mathrm{II} \% \mathrm{M}) \\
\text { Mean age: } 64 \mathrm{yrs}\end{array}$ & $\begin{array}{l}\text { 77.3\% Wrist } \\
6.3 \% \text { Hip } \\
0.5 \% \text { Vertebrae } \\
15.9 \% \text { Humerus }\end{array}$ & $\begin{array}{l}\text { Prior fracture: } 43(39.8 \%) \\
\text { Subsequent fracture I year post: } 3(2.8 \%)\end{array}$ \\
\hline Papaioannou(2000) ${ }^{17}$ & $\begin{array}{l}N=504(75 \% F, 25 \% M) \\
\text { Mean age F: } 81.5 \\
\text { Mean age M: } 75.7\end{array}$ & Hip & Subsequent fracture I year post: 50 (9.9\%) \\
\hline Khan $(2001)^{16}$ & $\begin{array}{l}N=112(83 \% F, 17 \% M) \\
\text { Mean age: } 64 \pm 13 \mathrm{yrs}\end{array}$ & Wrist & $\begin{array}{l}\text { Prior fracture: } 44(39 \%) \\
\text { Subsequent fracture } 6 \text { months to } 3 \text { years post: } 16(14 \%)\end{array}$ \\
\hline Juby $(2002)^{15}$ & $\begin{array}{l}\mathrm{N}=293(73 \% \mathrm{~F}, 27 \% \mathrm{M}) \\
\text { Mean age: } 85.7 \text { yrs }(66-97)\end{array}$ & Hip & Prior hip fracture: 54 (18.4\%) \\
\hline
\end{tabular}

Table 3: Prevalence of osteoporosis diagnoses and treatment in patients who have sustained a fragility fracture

\begin{tabular}{|c|c|c|c|c|}
\hline & Hajcsar $(2000)^{18}$ & Papaioannou (2000) ${ }^{17}$ & Khan $(2001)^{16}$ & Juby $(2002)^{15}$ \\
\hline \multicolumn{5}{|l|}{ Diagnosis (\%) } \\
\hline Clinical Diagnosis & 18.5 & 1.7 & - & 14.5 \\
\hline Densitometry & 22.2 & - & - & 3 \\
\hline Either of above & - & - & 50 & - \\
\hline \multicolumn{5}{|l|}{ Treatment (\%) } \\
\hline Calcium & 32.4 & - & - & 7.6 \\
\hline Vitamin D & 13.0 & - & - & 2.8 \\
\hline Calcium and/or Vit D & - & 4.7 & 61.6 & - \\
\hline HRT & 16 & 0 & - & 1.4 \\
\hline Bisphosphonates & 7.4 & 0 & - & 5.2 \\
\hline $\begin{array}{l}\text { Any osteoporosis-specific } \\
\text { therapy }\end{array}$ & - & - & 37.5 & 9.7 \\
\hline
\end{tabular}

among individuals experiencing a fragility fracture was less than $50 \%$, in most cases, much less. Fifty to $98.3 \%$ of individuals who experience a fragility fracture received no treatment for osteoporosis. Vitamin D supplement prescription was low despite research indicating that as many as $34 \%$ of Canadians are deficient $(<40 \mathrm{nmol} / \mathrm{L})$ [20]. Unfortunately, many individuals who fracture were not assessed or treated for osteoporosis. At the time the studies were conducted, bisphosphonates and HRT were rec- ommended therapies for the treatment of osteoporosis however, only a small proportion of patients with fragility fracture were prescribed these medications. The following therapies were available for prescription in 1995: etidronate as of July 1995, alendronate as of December of 1995 , and calcitonin was also available during the time the studies were reviewed. Raloxifene became available in Canada in January of 1999. 
Access to technology may present a barrier to osteoporosis diagnosis. The most commonly cited limitations to the use of densitometry in a survey of Ontario family physicians included the distance to the nearest densitometry facility and the cost of the test. However, the survey did note that physicians were following the guidelines for densitometry use where it was available [21]. In contrast, a study performed in Alberta demonstrated low use of densitometry for the prevention and treatment of osteoporosis in postmenopausal women, citing physician attitudes as important factors in decisions about screening and treatment [22]. A larger number of densitometry facilities exist in Ontario as compared to other provinces [21]. A lack of access to bone mineral density testing may play a greater role in an osteoporosis care gap in the remainder of Canada.

Although the diagnosis of osteoporosis after fragility fracture is important, it can only be effective in preventing future fracture if it leads to subsequent treatment of patients at risk. The proportion of postmenopausal women at an Ottawa hospital receiving osteoporosis therapy increased from $15.2 \%$ to $63.3 \%$ after a diagnosis of osteoporosis with densitometry [23]. Hip fracture patients in Alberta who were diagnosed with osteoporosis post-hip fracture were more likely to receive treatment $(48 \%$ vs. $5.5 \%$ ) [15]. In three British Columbia long-term care facilities, the mean calcium and vitamin D intake of those who had been diagnosed with osteoporosis met the 'adequate intake' level (1200 mg calcium, 600 IU vitamin D), compared to those without an osteoporosis diagnosis. In addition, those residents who had an osteoporosis diagnosis were more likely to have been prescribed bisphosphonates or HRT than those who had fractured but had not been diagnosed with osteoporosis [24]. These studies highlight the importance of a diagnosis of osteoporosis for future fracture prevention in those individuals who have experienced a fragility fracture.

A key message is that a prior fragility fracture is a major risk factor for subsequent fracture. The prevalence of a prior fracture in the articles we reviewed ranged from 18.4 to $40 \%$ of patients $[15,16,18]$. In the United States, $45 \%$ of women admitted with fragility fracture had experienced at least one prior fracture, one fourth of which were hip fractures [12]. Another study documented that 33\% of women admitted with distal forearm fracture had had a prior fracture [25]. The high risk of future fracture among the patients in the studies we reviewed was illustrated by the findings of a subsequent fracture in up to $14 \%$ of individuals. One study of women with hip fracture in the United States reported an incidence of $22 \%$ for any type of future fragility fracture [26]. These phenomena also occur in men. In one study, $30 \%$ of male veterans admitted with hip fracture had experienced a prior history of a fragility fracture, and $10 \%$ went on to experience a subsequent fracture [11]. It is essential that fragility fractures are identified as a risk factor for future fractures, and appropriate treatment measures are taken to reduce this risk $[3,4]$.

These conclusions are limited by the lack of prospective epidemiologic data. Chart reviews may miss data that were not recorded and patient interviews rely on patient recall, which can be inaccurate. In addition, the studies may only be representative of tertiary care centres. The studies attempted to include representative samples of patients experiencing fragility fracture. The communitybased hospital study included the smallest proportion (56.1\%), where most patients who were not included could not be reached, and a small number declined to participate. Another concern is that women may have been prescribed HRT for reasons other than osteoporosis, again pointing to the potential for over estimation of those diagnosed with osteoporosis and treated after fragility fracture. The study was limited to Canadian studies in order to avoid bias related to differences in the provision of health care services and/or available technologies. A survey of physicians in the United States, Canada and West Germany revealed that 73 percent of physicians in the U.S. reported that patients' inability to afford treatment was a serious problem, compared with only 25 percent in Canada and 15 percent in West Germany [27]. Future research should evaluate the whether an osteoporosis care gap is an international phenomenon. Finally, the studies reviewed are several years old, and it is possible that practice patterns may be improving.

\section{Conclusion}

The main message of this review is that despite the availability of a number of therapeutic options, many patients with fragility fracture do not undergo osteoporosis management, and are at high risk for subsequent fractures. The existing care gap between the occurrence of a fragility fracture and the diagnosis and treatment of osteoporosis requires multi-faceted intervention, such as a model for disease management, in order to reduce the incidence of fracture. Future research and education approaches should include strategies to address the barriers identified by family physicians and specialists in the diagnosis and treatment of osteoporosis, which include a lack of rationale for bone mineral density testing and confusion about management [28]. Improved communication between orthopaedic surgeons, specialists and family physicians with respect to patient follow-up may reduce the gap between fracture occurrence and osteoporosis management. In addition, strategies to involve the patient may be useful. Educational tools may aid patients in seeking osteoporosis screening from their physicians [29]. A paradigm shift is warranted, such that individuals over 40 years of 
age who present with fragility fracture should trigger a process of osteoporosis diagnosis and treatment in order to reduce the risk of another fracture in the future.

\section{Competing interests \\ Alexandra Papaioannou}

I have not received any funding for writing the review paper. I am or have been a consultant or on the speaker's bureau for the following: Aventis Pharma, Eli Lilly Canada Inc., Merck Frosst Canada, Novartis Pharmaceticals Canada Inc., Proctor and Gamble Pharmaceuticals.

\section{Lora Giangregorio}

None declared.

\section{Brent Kvern}

I have not received any funding for writing this paper. I am a family physician and have worked on educational research projects funded by Merck Frosst Canada, Aventis Pharma, Proctor and Gamble Pharmaceuticals, and GlaxoSmithKline.

\section{Pauline Boulos}

None declared.

\section{George loannidis}

None declared.

\section{JD Adachi}

I have not received funding for writing the review paper. I am or have been a consultant or on the speaker's bureau for the following: Aventis Pharma, Eli Lill Canada Inc., Merck Frosst Canada, Novartis Pharmaceuticals Canada Inc., Procter and Gamble Pharmaceuticals, and Pfizer Canada.

\section{Authors' contributions}

AP conceived of the study, participated in its design and coordination, and participated in the preparation of the manuscript. LG performed the literature searches and drafted the manuscript. $\mathrm{BK}, \mathrm{PB}, \mathrm{GI}$ and JA revised the manuscript and were consulted during the literature searches for inclusion of additional articles.

\section{Acknowledgements}

Dr. Papaioannou is an Ontario Ministry of Health and Long-Term Care Career Scientist. Lora Giangregorio is a bone scholar with the Canadian Institutes for Health Research. Dr. Boulos' research is supported by a combined CIHR/Arthritis Society Grant.

\section{References}

I. Hellekson KL: NIH releases statement on osteoporosis prevention, diagnosis, and therapy. Am Fam Physician 2002, 66:161-162.

2. Papaioannou A, Watts NB, Kendler DL, Yuen CK, Adachi JD, Ferko $\mathrm{N}$ : Diagnosis and management of vertebral fractures in elderly adults. Am J Med 2002, I I 3:220-228.
3. Davis JW, Grove JS, Wasnich RD, Ross PD: Spatial relationships between prevalent and incident spine fractures. Bone 1999, 24:26I-264.

4. Wasnich RD, Davis JW, Ross PD: Spine fracture risk is predicted by non-spine fractures. Osteoporos Int 1994, 4: I-5.

5. Brown JP, Josse RG: $\mathbf{2 0 0 2}$ clinical practice guidelines for the diagnosis and management of osteoporosis in Canada. CMAJ 2002, 167:SI-34.

6. Castel H, Bonneh DY, Sherf M, Liel Y: Awareness of osteoporosis and compliance with management guidelines in patients with newly diagnosed low-impact fractures. Osteoporos Int 200I, I 2:559-564.

7. Freedman KB, Kaplan FS, Bilker WB, Strom BL, Lowe RA: Treatment of osteoporosis: are physicians missing an opportunity? J Bone Joint Surg Am 2000, 82-A: 1 063-1070.

8. Gardner MJ, Flik KR, Mooar P, Lane JM: Improvement in the undertreatment of osteoporosis following hip fracture. J Bone Joint Surg Am 2002, 84-A: I 342-I 348.

9. Kiebzak GM, Beinart GA, Perser K, Ambrose CG, Siff SJ, Heggeness $\mathrm{MH}$ : Undertreatment of osteoporosis in men with hip fracture. Arch Intern Med 2002, 162:221 17-2222.

10. Onder G, Pedone C, Gambassi G, Landi F, Cesari M, Bernabei R: Treatment of osteoporosis among older adults discharged from hospital in Italy. Eur J Clin Pharmacol 200I, 57:599-604.

II. Riley RL, Carnes ML, Gudmundsson A, Elliott ME: Outcomes and secondary prevention strategies for male hip fractures. Ann Pharmacother 2002, 36: 17-23.

12. Simonelli C, Chen YT, Morancey J, Lewis AF, Abbott TA: Evaluation and Management of Osteoporosis Following Hospitalization for Low-impact Fracture. J Gen Intern Med 2003, 18:17-22.

13. Torgerson DJ, Dolan P: Prescribing by general practitioners after an osteoporotic fracture. Ann Rheum Dis 1998, 57:378-379.

14. Khan KS, ter Riet G, Popay J, Nixon J, Kleijnen J: Conducting the Review (stage 2): Study quality assessment (phase 5). CRD Report Number 4 Centre for Reviews and Dissemination, University of York; 200I:I-20.

15. Juby AG, Geus-Wenceslau CM: Evaluation of osteoporosis treatment in seniors after hip fracture. Osteoporos Int 2002, 13:205-210.

16. Khan SA, de Geus C, Holroyd B, Russell AS: Osteoporosis followup after wrist fractures following minor trauma. Arch Intern Med 200I, 161:1309-1312.

17. Papaioannou A, Wiktorowicz ME, Adachi JD, Goeree R, Papadimitropoulos E, Bedard M, Brazil K, Parkinson W, Weaver B: Mortality, Independence in Living and Re-fracture, One Year Following Hip Fracture in Canadians. J Soc Obstet Gynaecol Can 2000, 22:591-597.

18. Hajcsar EE, Hawker G, Bogoch ER: Investigation and treatment of osteoporosis in patients with fragility fractures. CMAJ 2000, 163:819-822.

19. Juby AG, Davis P: A prospective evaluation of the awareness, knowledge, risk factors and current treatment of osteoporosis in a cohort of elderly subjects. Osteoporos Int 200I, I 2:617-622.

20. Rucker D, Allan JA, Fick GH, Hanley DA: Vitamin D insufficiency in a population of healthy western Canadians. CMAJ 2002, 166:1517-1524.

21. Ridout R, Hawker GA: Use of bone densitometry by Ontario family physicians. Osteoporos Int 2000, II :393-399.

22. Suarez-Almazor M, Homik JE, Messina D, Davis P: Attitudes and beliefs of family physicians and gynecologists in relation to the prevention and treatment of osteoporosis. J Bone Miner Res 1997, 12:1100-1107.

23. Fitt NS, Mitchell SL, Cranney A, Gulenchyn K, Huang M, Tugwell P: Influence of bone densitometry results on the treatment of osteoporosis. CMAJ 200I, 164:777-78I.

24. Lee LT, Drake WM, Kendler DL: Intake of calcium and vitamin D in 3 Canadian long-term care facilities. J Am Diet Assoc 2002, 102:244-247.

25. Cuddihy MT, Gabriel SE, Crowson CS, Atkinson EJ, Tabini C, O'Fallon WM, Melton LJ,III: Osteoporosis intervention following distal forearm fractures: a missed opportunity? Arch Intern Med 2002, 162:421-426.

26. Bellantonio S, Fortinsky R, Prestwood K: How well are community-living women treated for osteoporosis after hip fracture? J Am Geriatr Soc 200 I, 49: I 1 97-I 204. 
27. Blendon RJ, Donelan K, Leitman R, Epstein A, Cantor JC, Cohen AB, Morrison I, Moloney T, Koeck C, Levitt SW: Physicians' perspectives on caring for patients in the United States, Canada, and West Germany. N Engl J Med 1993, 328:101 I-1016.

28. Jaglal SB, Carroll J, Hawker G, Mclsaac WJ, Jaakkimainen L, Cadarette SM, Cameron C, Davis D: How are family physicians managing osteoporosis? Quality study of their experiances and educational needs. Can Fam Physician 2003, 49:462-47I.

29. Papaioannou A, Parkinson W, Adachi J, O'Connor A, Jolly EE, Tugwell $P$, Bedard M: Women's decisions about hormone replacement therapy after education and bone densitometry. CMAJ 1998, I59:1253-1257.

\section{Pre-publication history}

The pre-publication history for this paper can be accessed here:

http://www.biomedcentral.com/1471-2474/5/11/prepub

Publish with Bio Med Central and every scientist can read your work free of charge

"BioMed Central will be the most significant development for disseminating the results of biomedical research in our lifetime. "

Sir Paul Nurse, Cancer Research UK

Your research papers will be:

- available free of charge to the entire biomedical community

- peer reviewed and published immediately upon acceptance

- cited in PubMed and archived on PubMed Central

- yours - you keep the copyright

Submit your manuscript here:

http://www.biomedcentral.com/info/publishing_adv.asp 